\section{Drugs and the brain}

\section{S. J. Enna}

Molecular Neuropharmacology. Editorin-chief G. N. Woodruff. Macmillan. 4/yr. £115.

As an integrated discipline, pharmacology has been quick to incorporate the tools of the biochemist and molecular biologist in its quest to define the mechanism of action of therapeutic agents. Neuropharmacologists have been particularly eager to use these approaches because the brain is less amenable to traditional study than other organ systems. With the growing interest in neuroscience, the number of papers dealing with the molecular basis of drug action has increased dramatically. Molecular Neuropharmacology was launched in mid-1990 as a vehicle for disseminating such information. Manuscripts covering this speciality have historically been scattered among several primary journals, including Molecular Pharmacology, Journal of Pharmacology and Experimental Therapeutics, European Journal of Pharmacology, Brain Research and Journal of Neuroscience. Although each is recognized as having high editorial standards, none is specifically for neuropharmacologists. The chief journal in this regard is Neuropharmacology, which has a broader mandate than Molecular Neuropharmacology. So it would seem that this offering addresses a real need and, given the number of excellent workers in the field, has the potential to develop into a primary journal. This possibility is enhanced by the fact that the editorial board is composed of an international group of highly acclaimed neuroscientists and neuropharmacologists.

During the first two years of publication, four issues of Molecular Neuropharmacology have appeared. Eleven months elapsed between the first and second, with three months separating the third and fourth issues. The quality of the articles is generally good, many contributed by leaders in the field. But as is the case for most new journals, it would seem that these authors are still submitting their best work elsewhere. Nonetheless, if Molecular Neuropharmacology can begin publishing on a regular schedule and continue to attract authors of this calibre, it should ultimately find a loyal audience.

Given its stage of development, price and past publication record, it is difficult at this time to recommend the journal for individual subscribers. It certainly has a place in biomedical libraries, as the quality of the published articles is NATURE · VOL 359 - 1 OCTOBER 1992 such that they will be cited in the primary literature - access to the journal will therefore be required by many investigators.

S. J. Enna is in the Department of Pharmacology, Toxicology and Therapeutics, University of Kansas Medical Center, Kansas City, Kansas 66160, USA.

\section{Going like a dream?}

\section{Eric A. Barnard}

Current Opinion in Neurobiology. General editors Albert Aguayo and Martin Raff. Current Biology. 6/yr. £209.95, $\$ 445$ (institutional); $£ 69.95, \$ 129.95$ (personal); £29.95, $\$ 49.95$ (student).

A FAMOUS newspaper once claimed to contain "all the news fit to print" - a claim long since outdated as far as the 'all' is concerned, not to mention the 'fit'. Similarly, the claim of this journal that it reviews "all advances" in "the entire field of neurobiology" and gives a "comprehensive listing" of the literature can be taken as an impossible dream. The journal divides the field into main sections, one per issue, repeated cyclically every year: development; cognitive neuroscience; signalling mechanisms; sensory systems; neuronal and glial cell biology (half an issue) and disease, transplantation and regeneration (half an issue); and neural control. The issues are necessarily selective, each consisting of a set of 'topics' or brief reviews, usually four pages in length, which inevitably cannot include all the advances of the past year.

For example, in the issue on signalling mechanisms we find the topic of Gprotein-coupled receptors. That is hardly a surprise, but this year's review of that topic is confined to dopamine receptors (albeit done well and comprehensively, by D. K. Grandy and O. Civelli), and the bibliography there of "the papers of the greatest interest over the previous year" is also confined to these receptors. Therefore, less than one per cent of the G-protein-coupled receptors can actually be reviewed in one year of this journal.

Let it be said immediately, though, that the scientific standard of the journal in general is very high, and the overall editing of each issue is done with care and insight. The ability of the section editors to get many experts to write the almost uniformly excellent reviews, and to do so in a timely manner, is creating a success for this considerable enterprise.

Review journals for the neurosciences are certainly becoming more numerous. Do we need another one? Of the conventional type, most of us would think not. The same is true of the Trends type. Current Opinion, however, is something else again. It uniquely fulfils a need. First, by means of the planned annual cycle of reviews, readers know in which issue, for example, glial cells or neurodegenerative disease or cognitive systems will be covered. They need no longer scan the contents lists of a variety of review journals to see what the lottery of topic selection has brought up.

Second, there is an exceptionally wide coverage of fields, although it does seem to me that the balance struck underrepresents the proportion of publications on molecular aspects. This is exemplified by the lack of space for reviews of most G-protein systems and of the molecular biology of the glutamate receptors (only the sections recur each year, not all the designated topics within each). Examples of topics unrepresented this year in the signalling issue are potassium channels, transmitter transport, ionic exchangers and pumps.

Third, each issue contains a "complete bibliography of world literature" on the fields the issue embraces. The list covers one year, ending five months before the publication date, but is not quite as comprehensive as claimed. Sampling just some of the topics in the 82 pages of bibliography for the excellent June 1992 issue edited by P. Ascher and C. Stevens on signalling mechanisms, I found several relevant articles missing. Established journals not covered include European Journal of Pharmacology, Molecular Pharmacology, The New Biologist, Biochemical and Biophysical Research Communications and FASEB Journal; instead, some less-read journals are used. The field of neurotransmission is only partially covered.

These limitations can and should be partially remedied. In addition, a distracting practice is the requirement for each reviewer to rate the papers cited for their interest; two points, one point or (for most) none. This is appropriate for a restaurant guide, but $I$ feel it is invidious here. One or two reviewers bestow a good proportion of the few two-star ratings on their own papers. Some avoid one-star ratings; others completely omit two-stars, presumably owing to an understandable embarrassment. I urge the editors to drop this highly subjective system. Reviewers wishing to draw attention to a paper can do so with more clarity in the text of their articles. And it would be helpful to non-experts 